\title{
Letter to the editor concerning "hepatic myelopathy with spastic paraparesis: report of two cases and review of the literature" by S. Ben Amor et al. (Eur Spine J. 2013, Jun 1)
}

\author{
Raffaele Nardone $\cdot$ Stefan Golaszewski $\cdot$ \\ Yvonne Höller · Francesco Brigo $\cdot$ Eugen Trinka
}

Received: 19 June 2013/Revised: 3 August 2013/Accepted: 3 August 2013/Published online: 21 August 2013

(c) Springer-Verlag Berlin Heidelberg 2013

To the Editor,

We read with great interest the article by Ben Amor et al. [1] published in the European Spine Journal entitled "Hepatic myelopathy with spastic paraparesis: report of two cases and review of the literature". The authors state in their paper that there is no special diagnostic tool for hepatic myelopathy (HM), and that the diagnosis has to be established on clinical grounds after exclusion of other possible entities. However, in our opinion, there is a noticeable omission in this important article. Our previous study [2] revealed that motor evoked potentials (MEP) elicited by transcranial magnetic stimulation (TMS) may be very helpful in the diagnosis of this rare complication of chronic liver diseases that is usually associated with a portosystemic shunt and likely to be overlooked. The authors demonstrated that central motor conduction studies by means of TMS are sensitive, accurate and easily applicable methods for detecting even a subclinical damage of the corticospinal tract. The threshold for corticospinal electrophysiological abnormalities was below that for clinical and/or radiological changes. Spinal cord involvement was evident even at the preclinical stage and became

R. Nardone $\cdot$ S. Golaszewski · Y. Höller · E. Trinka Department of Neurology, Christian Doppler Klinik, Paracelsus Medical University, Salzburg, Austria

R. Nardone $(\varangle) \cdot$ F. Brigo

Department of Neurology, Franz Tappeiner Hospital, Via

Rossini, 5, 39012 Merano, BZ, Italy

e-mail: raffale.nardone@gmail.com

R. Nardone · S. Golaszewski · Y. Höller · E. Trinka Spinal Cord Injury and Tissue Regeneration Center, Paracelsus Medical University, Salzburg, Austria more overt as the disease progressed. Most of the examined patients did not have clinical symptoms and presented only physiological subclinical abnormalities.

MEP studies may thus disclose an impairment of the corticospinal pathways even before HM is clinically manifest and enable an early diagnosis of HM. Since, liver transplantation (the first therapeutic option) should be performed before spinal cord damage becomes irreversible [3-5], the diagnosis of HM must be established as early as possible to enhance the chance of a complete recovery of the spinal cord. Therefore, we believe that such an important examination, which is at present widely and easily performed in the most neurophysiology laboratories, cannot be neglected. We found important to highlight that, especially in a review article on HM, this important diagnostic tool should be included and discussed.

Conflict of interest None.

\section{References}

1. Ben Amor S, Saied MZ, Harzallah MS, Benammou S (2013) Hepatic myelopathy with spastic paraparesis: report of two cases and review of the literature. Eur Spine $\mathbf{J}$ [Epub ahead of print]

2. Nardone R, Buratti T, Oliviero A, Lochmann A, Tezzon F (2006) Corticospinal involvement in patients with a portosystemic shunt due to liver cirrhosis: a MEP study. J Neurol 253:81-85

3. Counsell C, Warlow C (1996) Failure of presumed hepatic myelopathy to improve after liver transplantation. J Neurol Neurosurg Psychiatry 60:590

4. Troisi R, Debruyne J, de Hemptinne B (1999) Improvement of hepatic myelopathy after liver transplantation. $\mathrm{N}$ Engl J Med 340:151

5. Weissenborn K, Tietge UJ, Bokemeyer M, Mohammadi B, Bode U, Manns MP, Caselitz M (2003) Liver transplantation improves hepatic myelopathy: evidence by three cases. Gastroenterology 124:346-351 